\title{
King Ranch Institute for Ranch Management Symposium on Ex- cellence in Ranch Management
}

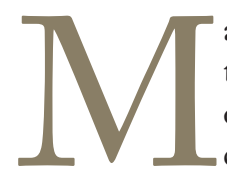

anagement of rangeland resources has proven to be challenging because of the complexity of the resources themselves and the divergent demands of dynamic societies. In the last quarter of a century, much of the focus of the management of these resources has been with processes like ecosystem management, Holistic Resource Management, and Integrated Resource Management. A logical next step is the application of a relatively simple but highly effective tool known as the Balanced Scorecard.

The Balanced Scorecard was first introduced to the business community in the early 1990s by two Harvard Business School professors, Drs. Robert Kaplan and David Norton. It has been successfully adopted by organizations of all types and in countries around the globe. The Balanced Scorecard has been recognized as one of the most important concepts in business in the 20th century. Its application to the management of rangeland resources is not only logical but also criti$\mathrm{cal}$, as the expectations of both the ranching businesses based on their use and governmental organizations charged with their care are broadened and deepened by various stakeholder groups. Seven of the articles in this month's Rangelands were papers presented by the speakers at the 2006 HOLT CAT/ King Ranch Institute for Ranch Management Symposium on Excellence in Ranch Management. The theme of the symposium was "Business Planning for Successful Ranch Management."

The goal of the symposium was to introduce rangeland managers to the Balanced Scorecard. The keynote speaker was Nicola Shadbolt, Senior Lecturer in Farm and Agribusiness Management, Massey University, New Zealand. Ms. Shadbolt is the world's leading expert in applying the Balanced Scorecard to farm and ranch management. Using a workshop format, the attendees rotated through a series of breakout sessions designed to help them apply this tool to the different perspectives that contribute to a ranch, such as: wildlife management, natural resource management, livestock production, and human resources. Each session was led by a team of successful ranchers and experts in the topics they discussed. They were assisted by students in the King Ranch Institute for Ranch Management. DVDs of the 2006 symposium can be obtained by contacting the Institute at 361-593-5401 or emailing krirm@tamuk.edu.

The goal of publishing these papers in Rangelands is to expose a broader audience to the Balanced Scorecard and to widen its potential adoption. The management of rangelands is the responsibility of a wide array of professionals. The Balanced Scorecard can be an effective tool in all of their management tool boxes.

Barry H. Dunn, Guest Editor Rangelands, Executive Director and Robert J. Kleberg Jr. and Helen C. Kleberg Endowed Chair, King Ranch Institute for Ranch Management, MSC 137, Texas A\&M University-Kingsville, Kingsville, TX 78364, (361) 593-5400,kabbd00@tamuk.edu. 